\title{
The human conscience between witnessing and discernment: Heidegger, Ricoeur and beyond
}

\section{ROBERT GRZYWACZ}

Jesuit University Ignatianum in Krakow robert.grzywacz@ignatianum.edu.pl

ORCID: 0000-0001-8353-6238

\begin{abstract}
The paper deals with the problem of human conscience as an attentional mode of being that effectuates an original capacity for discernment. Such an undertaking, after the necessary terminological and phenomenological clarifications, requires one to cope with its specific background, especially the critique of the moral worldview and the postmetaphysical setting of contemporary thinking. Taking into consideration the Heideggerian view of the matter, I reflect on the doubts Ricoeur addressed to the former, and take advantage of Ricoeur's early philosophy to reinterpret and develop his own stance as expounded in Oneself as Another. His later work on ideology and utopia may contribute to helping to establish some criteria for the functioning of the conscience.
\end{abstract}

Keywords: discernment, attention, original affirmation, temporal mediation.

\section{Introduction}

The present study is principally concerned with a theoretically and practically problematic anthropological issue stemming from a serious consideration of the phenomenon of responsibility, namely human conscience. I argue here that the phenomenon of conscience, in its merely anthropo- 
logical scope, is to be regarded as overpassing the simple question of morality in the sense of a value judgement which renders things as being in "bad" or "good" conscience. In this regard, I supplement the well-known view of Heidegger with the stance of Ricoeur, and propose to enlarge the understanding of the phenomenon. This is to be done in terms of the aspect of an intuitive insight concerned with a kind of absolute witnessing - hidden behind the metaphor of "voice" coming from above, which forms an evaluative judgment in becoming - what requires more specific elucidation. I proceed to elucidate my view on the motivational and attentional mode of understanding human conscience. Then I attempt to verify such a stance on a practical basis by describing how the functioning of the conscience, transferred into a temporal perspective, modifies the way one acts so as to permit one to approach an absolute. In this respect, I go beyond Ricoeur's explicit view on conscience, even if I refer to his thought throughout as a whole.

\section{The problem of conscience after the Heideggerian critique of metaphysics and moral worldview}

Ricoeurian philosophical anthropology, and principally his "little ethics" and subsequent study of multi-faceted otherness, seem to constitute a favourable context to reflect on the problem of human conscience. It is so because his manner of treating the phenomenon of conscience presents an attempt to confront some of its crucial difficulties, namely: 1) the suspect character of certain aspects of the analysed phenomenon, especially those connected to a moral worldview; 2) the defendable meaning of some traits which are distinctive for conscience in its pre-moral version such as injunction and debt - in comparison with a reflective ontological-epistemological self-attestation as to one's identity; 3) the reducibility of conscience to the type of otherness represented by other people (Ricoeur 1992, 341).

Neither the first nor the third difficulty is the target of the current study. It is important to notice that for Heidegger in Being and Time the moral vantage view is a feature of the vulgar interpretation of conscience, 
and this interpretation ultimately appears to be a product of the "public conscience”, i.e. of the voice of the they (das Man - Heidegger 2010, § 57, 267 [278]). Hence, the author determines conscience as being "in its essence, in each instance mine" (Heidegger 2010, 267 [278]), and by the same token, criticises its inauthentic (not genuinely mine but reflecting a common-sense view), everyday moral understanding as intrinsically bound up with the public dimension.

Ricoeur formulated a famous and essential critique with regard to this Heideggerian stance (Ricoeur 1992, 350-355; 2008, 108-110; Lubowicka 2000; Ziółkowska 2007). At its core, this critique remains valid. Yet while his crucial point was to identify the inner anthropological structure that is at once mine and somehow alien to me, which structure conditions the moral obligation in general, his account in the quoted works can even be read as forfeiting the earlier Heideggerian achievements, in other words as a backward step. My contention at this point is that such a reading would be fundamentally false. Furthermore, a closer examination of the issue also delivers a broader view on conscience itself.

\section{Conscience and the absolute testimony of the absolute}

In order to prevent us from losing the achievements of Heidegger, they can serve as guidelines for the current investigation. The author of $\mathrm{Be}$ ing and Time insisted on the extension of the range of conscience when criticising its merely moral and vulgar interpretation. As he stated, it requires a specific type of hearing, and thereby a special mode of being, namely one of reticence, which supposes that "the public idle chatter of the they" (Heidegger 2010, § 57, 266 [277]) is stopped, and allows silence to be retained and for us to remain in the soundless of uncanniness. What is thus made possible is an action taken by the most authentic self in itself, just by its letting be. Ricoeur's own contribution consisted of emphasising an indispensable critical capacity of discernment, constitutive for conscience as a unique anthropological factor irreducible to, and different from, its social account (e.g. superego). 
However, such an account seems to be incomplete. Moreover, the Ricoeurian hermeneutics of testimony deserves consideration as a more adequate understanding of the functioning of conscience. ${ }^{1}$ What grounds does Ricoeur proffer to maintain that this close, yet subtly different, concept matches our description of conscientious action? Precisely such a reason may be found when he speaks of Levinas as a thinker of testimony, comparing him with both Heidegger and Nabert (Ricoeur 1995, 108-126). As we could see above, any reference to the latter is absent in Oneself as Another. In the text devoted to Levinas, which was nearly contemporaneous with the aforementioned work, Nabert's contribution appears in a mediatory position between the Heideggerian stance (highlighting the dimensions of Height and Exteriority when discbribing conscience, while neglecting its Transcendence and Alterity) and the Levinasian one. In the last view all the notions are hyperbolic, without rapport to any ontological condition of one's identity. Nabert, even if closer to Levinas than Heidegger, supplies us with an insight which is absent in Levinas. This is precisely why his reflexion on testimony turns out to be relevant to the aim pursued here.

In Nabert's thought, the scope of Exteriority is enlarged, and the dimension of Height becomes interiorized, even if not entirely. Both observations have a crucial impact on the grasp of conscience. Unlike Levinas, Nabert (and Ricoeur who follows him in this regard) considers exteriority in terms of a historical and contingent encounter with signs - that is to say, acts, works, and lives - that testify to the absolute (Ricoeur 1980, ch. 2). It may take the form of the experience of the Other's face (in the Levinasian sense), but not exclusively. Such an exteriority manifests the aspect of height as well, i.e. an excellence of some deeds, works or lives. As to the dimension of height, it has its inner counterpart which is termed original affirmation. The latter is an act that denies the limitations of individual consciousness and thus attests to the absolute, in the sense

Hereafter, I use the terms "testimony" and "witnessing” interchangeably, given that the author himself admits such a practice by distinguishing three dimensions of testimony: 1) someone's acts, deeds, conduct; 2) witnesses of these acts or attitudes; 3) the interior reflexion recognising the capacity to witness as to the pure interior act of original affirmation (Ricoeur 1995, 108-126). 
of making its testimony receivable. However, what specifies such a particular affirmation is its merely internal character, and consequently, its weakness as regards its external expression, and even an internal maintenance that would overpass its inescapably inaugural and momentary characteristics. It is similar to an act of awareness. That is why having recourse to an exteriority becomes ineluctable: such an act requires an interpretative translation into some predicates or qualities by means of which it can be spoken of (Ricoeur 1980, ch. 3). Therefore, inasmuch as one believes it might be justified to treat the original affirmation as an equivalent of conscience, the description of its inner act corresponding with outer signs can depict the conscientious functioning in terms of the capacity of discernment.

If the original affirmation consists, therefore, in the core critical capacity of the subject, or in other terms, in one's inner differentiation, a distancing of oneself from oneself that permits self-transcendence, this constitutive discrepancy in itself is nothing other than the confrontation with nothingness understood as the subject's limitations. As such, in its primarily negative character, it depends on the exteriority of meaningful events, by means of which it becomes specified "at the price of the most extreme attention" (Ricoeur 1980, ch. 3). The last remark on the role of attention seems to be significant, and at least is regarded as such in the current investigation.

Conscientious discernment is a process in which "original affirmation changes into a criteriology of the divine”, i.e. the aforementioned translation into some predicates (Ricoeur 1980, ch. 3). This process means an inner regeneration of self-consciousness, a regeneration simultaneously motivated by the inadequacy of one's actual consciousness in comparison with his/her original affirmation, and the testimony of their possible adequacy acknowledged as being realised in an outer sign. In this regard, the purer consciousness (conscience) becomes, the more receptive it is to the historical presence of the divine, and more capable it is of affirming it.

Furthermore, given that conscience works to regenerate human subjectivity (by means of in/adequacy of its actual state and its original affirmation), to unbind its charging bond to the past (called phenomenologi- 
cally debt), it requires a constantly renewable recalling to the resources of life that still remain unexplored (Ricoeur 2006, 381, 438-443, 489-493, 503). These resources could perhaps be identified, for our purposes, with the original affirmation in its experiential aspect. They are but the object of witnessing. It seems that Ricoeur himself legitimizes such a reading by emphasising an ineluctable asymmetry when examining the question of pardon (Ricoeur 2006, 466-470).

\section{Conscience and attention - anthropological foundations}

Nevertheless, the Nabertian term of original affirmation does not seem to be the only way of speaking of conscience if one would like to advance Ricoeur's attainments further. In the following, final section, I develop the thesis that the early phenomenological-eidetic reflexions of the author of Freedom and Nature deliver precious support in the matter, especially when coupled with the posterior explorations focused on time. That attention is connected with conscience should not surprise one familiar with the ancient tradition of the practical examination of the conscience - something essentially connected with paying attention to oneself (prosoche - Hadot 1995, 130-140; Foucault 2014, 91-161). It is primarily the case since attention, in conformity with what some contemporary thinkers have pertinently ascribed to conscience (Spaemann 2006, 164-179), can be called openness to self-transcendence. The presence of such a view in Ricoeur is quite striking.

For the French philosopher, attention actually equals reason in action (volition), in its free, spontaneous mode of operation ${ }^{2}$. It is the very mark of subjectivity insofar as a sign of its mastery over time, over the temporal succession in the course of experience (Ricoeur 1966, 149-163; 2016, 23-52). In other words, attention, according to Ricoeur, is the capacity to conduct and stop the internal debate at any moment, fixing the attentional focalisation on a particular aspect of things or ideas, or on a specific reason (motive) for action etc. Its principal advantage as concerns us here

2 Some of the following ideas were presented in a skatchy and more dispersed way in my book Świadek przekonań - podmiot sumienia. Paul Ricoeur i filozofia świadectwa (2020). 
is that it brings together the traits that earlier characterized conscience. First of all, attention brings together the highest activity and the greatest receptivity (Ricoeur 1966, 155). The highest activity, because to pay attention to something is not only to actively extract it from its background, but also to keep oneself indeterminate enough to be continuously able to consider something else (Ricoeur 1966, 186). The greatest receptivity, since such an indeterminacy means that one remains susceptible of wonder, of an unexpected meaning, of a still deeper value insight, and of a broader range of reasons etc. Can one reasonably hold that this capacity, understood in a large sense not merely intentional, differs essentially from that of potentially the most complete self-divestment, of becoming susceptible to the divine? As far as active perception is a matter of attention, one can find its work also in the ability to stop the consideration of mental entities, i.e. the process of deliberation, which may be identified with a germ of judgment. Such a multidimensionality of attention seems to coincide well enough with the main distinctive features of conscience reflected upon in terms of the original affirmation.

Having recourse to attention helps us to understand more precisely how it is possible that the same factor can be endowed with the nature of act (i.e. immediacy), and concurrently be an inchoate judgment. Attention neither changes nor creates reality, but selects, extracts and highlights some of its aspects - and thus differs from any anticipatory influences, but also from becoming fascinated by the object to the point of losing selfcontrol. Attention freely separates the confounded dimensions of experience by relating them to distinct values and, inversely, it reunites the scattered experiential elements by referring them to simple values or a unique value. As a result, it clarifies the motivational dynamics which may be divided into feelings and reasons (Ricoeur 1966, 158-160).

Imagination plays a specific mediatory role in this process. Ricoeur speaks in this respect of "the universally imaginative character of attention" (Ricoeur 1966, 150). This implies that attention allows us to see in a broader sense of the term, to "develop intuitively all the relations and all the values" (Ricoeur 1966, 150), making it possible to attempt even the most abstract of them. The importance of such a testing of values in im- 
agination, with the employment of an attentional focus, lies in the fact that it serves to elucidate even those aspects of the lived motivational process that are beyond voluntary control. For this reason, it is entirely legitimate to hold that taking the multidimensional role of attention into consideration results in overcoming "the false dilemma of intellectualism and irrationalism" by means of the respectfulness of "the infinite richness of [...] motivation" (Ricoeur 1966, 156, 163).

\section{The difference between attention and reflexion}

The attentional examination of mental objects enables oneself to act in a more effective way (which can sometimes also mean to suffer something). The problem of the criteria of the effectiveness in question must be skipped now and deferred to the final part. Instead, what counts for us at this point, and what Ricoeur tries to establish, is that this multifaceted and imaginatively supported notion of attention differs in essence from reflexion. As he observes, attention "remains that vision, that silence in which all voices echo [...] which creates time, wins time, so that all these voices speak distinctly, that is to say, in a succession" (Ricoeur 1966, 163). The creation of time to let different voices speak is one thing; forming a judgment and reasoning is quite another. ${ }^{3}$ Why should this difference be considered so crucial?

With this question, one can rediscover the significance of the aforementioned indefiniteness of attention. The relation between this indefiniteness and making a choice is the one of mutual interdependence, of mutual implying. According to the author,

there is an indetermination of the self, subsisting in decision, which is the continuing ability to consider something else, and there is a determination of the self, subsisting in indecision, which is the forward movement of the act

3 In Ricoeur's words: “Our acts depend on our judgments but our judgments depend on our attention. We are masters of our judgment because we are masters of our attention" (Ricoeur 2016, 47). Hence, as showed it convincingly Michael A. Johnson, one of Ricoeur's merits consists in a synthesis of the Cartesian attention tradition with Husserlian phenomenology (Johnson 2018, 79-108). 
itself, moving on to consider something else". Consequently, "determination and indetermination are strictly contemporaneous and concern the very irruption of acts of valuating and choosing (Ricoeur 1966, 186).

It follows from this that the domain of attention encompasses the very emergence of evaluation and choice or, as said beforehand, simply an inchoate judgment. What Ricoeur presupposes here - let us recall that the point is eidetic research - is this freedom one constantly preserves towards his/her motives which only "incline without compelling" (Ricoeur 1966, 187). Therefore, one remains capable of looking at the most evident motive or not, at this one or another, and so on.

In such a role of an elucidating factor - in the eidetic perspective - attention seems not only to remain continuously operative but to be even necessary. Otherwise, the broad spectrum of various experiences concerning auto-correction by means of one's own resources, including autotherapy or self-regulation, would be inexplicable. ${ }^{4}$ This is because one of the essential traits of attention lies in its ability to neutralise, albeit progressively and only to some degree, the impact of the past, of the traces of older acts (Ricoeur 2016, 37-38). ${ }^{5}$ In an actual realisation, such a neutralising capacity sometimes requires an effort. This effort becomes manifest

in 'creating silence' in the resistance the self meets from itself in its own act of choice, the effort needed to 'turn off' the din of the vivacious allure of sensuous motives to hear the less lively, but more ideal motive. The paradox of choice is that it depends on listening to the right motives, the right evidence, and this involves effort (Johnson 2018, 103).

But this internal reviewing of even the right motives, to be effective and come to a decision, cannot consist in endlessly turning round, doubting the evidence, suspending the presence of an idea or regarding something else. The critical pole of the endeavour meets its limits in the opposing

4 In such a therapeutic context, attention is called mindfulness (e.g. Hayes and Smith 2005, 6-7, 94-119).

5 The influence which, in cognitive psychology for example, is called priming (Zimbardo, Johnson, and McCann 2017, 171). 
pole, namely in forming a conviction. As far as attention is concerned, one could speak of this dialectic in terms of mobility and stopping (Ricoeur $2016,46)$, where the latter equals to "the vanishing of any 'buts", to a real detachment thanks to which "these 'buts' fall out of the field of attention" (Ricoeur 2016, 49).

With these observations, it becomes clear that one needs some criteria to discern the moment of stopping the consideration of motives, and by the same token, those permitting one to privilege a specific motive. It also results from the current attainments that the core of responsibility lies in directing attention in the proper way. Furthermore, it is because of the possibility that the attentional capacity remains unused - or misused - that the experience of remorse can happen (Ricoeur 2016, 50-51; 1966, 188). There is a fundamental difference between a kind of retrospective (and somehow spatializing) illusion and the authentic feeling that one could have done otherwise. But this difference is phenomenological in nature, and cannot be overruled by the viewpoint of causality - since maintaining the presence of some ideas differs from the mastery over their intrinsic interconnection: "The wasted or lost possibility arises [...] as a living reproach: [...] accuses me" (Ricoeur 1966, 163; 2016, 41, 43). It follows that attentional power eludes all attempts to think of it in terms of something invented after a deed - which would indeed be the work of reflexion! - and requires it to be acknowledged as a discovery and immediate datum. In other words, even an act of the demission of one's freedom like some regrettable deed that means a deficiency in using the "power which could have been devoted to a betrayed value” (Ricoeur 1966, 188) is identified with an active demission, followed by the lived "shadow" of used and unused potency. The above description of qualms or the pricks of conscience seems to converge well with the original affirmation. Moreover, this attentional power also fits the sketchy characteristics of the unexplored resources enabling the unbinding of the agent from his/her act. All of this argues in favour of a specific grasp of the mediatory function of conscience. This would consist of mediating between an innocence of perception (in a broader sense, related to the experience of self-divestment), and accumulated past experience which tends to lead to the repetition of 
acquired schemas. The very efficacy of such a mediation depends on the possibility of a really lived renewal, which implies the indispensability of understanding conscience in terms of something deeper than reflexion. One becomes the possibility he/she unceasingly opens up in him/herself.

It should be underscored that attention is not reflexion. The latter presupposes the former, so the former is more fundamental, even if only in the sense of an experiential priority, than the latter. It is true that reflexion remains necessary in order to articulate attentional experience, to assure the integrity of being human. Yet at the same time, it stops, suspends, "puts into brackets" the living drive that constitutes the mark of subjectivity. Ultimately, the unique nature of attention lies in its remobilising power, something which enables one to regain a lost drive and, by the same token, makes action possible (Ricoeur 1966, 188-190).

\section{The problem of criteria for stopping discernment}

Accordingly, conscience understood in terms of the attentional mode of being oneself, functions so as to create time, to win time, "so that all [...] voices speak distinctly, [...] in a succession" (Ricoeur 1966, 163). Time is not only implied here, but essential, and it makes responsibility a matter of permanent becoming. It contributes to the formation of one's identity that can be determined in Ricoeurian terms as self-constancy (Ricoeur 1992, 123-124, 294-296). In this respect, conscience functions in a way that may be compared with the "threefold mimesis" of action (Ricoeur 1984, 52-87). The naïve perception in the starting phase should pass through that of iconic augmentation (Ricoeur 1984, 80-83), by an interruption of the course of action, by the most complete detachment possible from the real and listening to all the unfamiliar voices, in order to receive, thanks to this pause, a new impetus to action by reorienting it (Ricoeur 1988, 179).

Conscience grasped as attentional capacity, therefore, plays a mediatory role within the lived time. This is because the very phenomenon of responsibility manifests essentially temporal traits and thus covers three dimensions: past, present, and future. A specific concept-pattern corre- 
sponds to each of them: the bearing of acts, as to the future; debt, as regards the past; and account, concerning the present (Ricoeur 1992, 294-296). What does this temporally-oriented mediation consists of?

As Louis Roy convincingly argues (Roy 2003), the Ricoeurian reader needs some criteria that would help him/her discriminate between fruitful and deleterious (textual, which may be generalised) testimonies, between the veracity and falsity in them (Roy 2003, 301). He proposes a promising task to be effectuated, namely to examine the philosopher's contributions on ideology (Ricoeur 1986; 1991, 308-324) and false consciousness in this regard, as well as his text on religion and symbolic violence (Ricoeur 1999). What results from such an examination in relation to the functioning of conscience?

The mediatory role of conscience with regard to time resembles, for the most part, that of practical judgment in a given situation. ${ }^{6}$ This attentional mode of being oneself helps to recapitulate, within the living historical and nonpointlike present, and through the idea of an account, the overall responsibility which includes equally past indebtedness and the future consequences of one's acts (Ricoeur 1992, 295-296). More concretely, but still in rather general terms, it means that mediation in question refers to what one could call, following Reinhart Koselleck, the "space of experience" and "horizon of expectation" (Ricoeur 1988, 208-235). To be concise, the former may be identified to some extent with the debt inherited from the past, while the latter is correlated with the future bearing of one's acts. It is precisely at this point that the criteria yielded by the reflection on ideology and utopia come into play.

What is essential in Ricoeur, and admits the current application, is the consideration of ideology as "constitutive of the dimension of praxis" (Ricoeur 1986, 10), and by means of the symbolic mediation of action and of the human mode of existence as a whole. Furthermore, the core purpose that ideology serves in this context, seems to be reducible to its function of legitimising an authority, which thereby contributes to the identity-referred integration (Ricoeur 1986, 11-13). The phenomenon of

6 This claim cannot really be surprising for one who keeps in mind Ricoeur's statements as concerns the similarity of both (Ricoeur 1992, 312, n. 15; 352). 
utopia, in comparison with that of ideology, can be structured in a similar way. It turns out then that it delivers "an empty place from which to look at ourselves" (Ricoeur 1986, 15). Thus it opens up the field of the possible beyond the actual, in which some alternative ways of living may appear thanks to the imagination. In this kind of neutralisation, the function of a "nowhere" becomes operative as the opposite of ideology. Authority is here put into question by possibly the most complete divestment in relation to the status quo. Briefly, and in Ricoeur's own words: "There is no [...] integration without [...] subversion" (Ricoeur 1986, 16-17). ${ }^{7}$ A sort of typical pathology corresponds to each term of the pair: it is dissimulation in regard to the real action (a distorted picture of reality) in the case of ideology, and escape from reality (in favour of fiction), as far as utopia is concerned. Taken together, both directly pave the way to the soughtafter criteria.

If the deleterious logic of the respective pathological attitudes consists in establishing the alternative between all or nothing - the incapacity of taking into consideration a "nowhere" or that of taking into account the "here and now" of a particular situation - then the dialectical relation between ideology and utopia seems to supply a remedy (Ricoeur 1986, 17). More precisely, regarding the enclosing tendency that characterises ideology, utopia provides "a critical tool for undermining reality", "to break through the thickness of reality" (Ricoeur 1986, 309). In consequence, some unknown or unexplored possibilities lying in reality, not only subversive but also projective, become accessible. Nevertheless, they do not come from nowhere, nor do they start nowhere. It remains necessary "to cure the illness of utopia by what is wholesome in ideology" (Ricoeur 1986, 312), namely the element of identity, of belonging, of conviction, of drawing from tradition. Within such an approach, a value-free attitude turns out to be impossible, or at least futile. Verification only comes from the wholeness of one's life. It stems from this that the most important criterion for action is that of appropriateness, i.e. of prohibit-

7 By deleting the adjective "social", I intend to make the quotation more relevant to the context in which the more individual capacity is analysed. This modified thesis remains equally true in Ricoeur. 
ing the incongruity of ideology and utopia from going too far (Ricoeur 1986, 313-314). The implementation of such a criterion takes the form of a situational judgement.

\section{Conscience's mediatory function in temporal experience}

When the criterion is carried over to the functioning of conscience in regard to possible action, the implication of time becomes evident. Let us briefly clarify the shift performed here. In this case, one is situated within the "time with a present", "the self-referential present" (Ricoeur 1988, 91), the lived experience conditioned by the "qualitative difference between fact and possibility" (Ricoeur 1988, 298). From such a perspective, the future signifies "the future-become-present" (Ricoeur 1988, 208) while the past - the "being-affected by the past" (Ricoeur 1988, 216-217). In other words, both temporal dimensions meet each other within the present. The present in question is the time of making present, and of initiative (Ricoeur 1988, 230). What follows from the reflexion on initiative within the lived present is the essential difference between the perspective of an observer and that of an agent; between observing something that happens and making something happen; between testimonies in the sense of natural vestiges and the testimonies of human deeds (Ricoeur 1988, 91, 231). Initiative can be placed between them - in a mediatory position. That is why it fits well in comparison to the temporal functioning of conscience.

At this stage, it is already possible to reintroduce the criterion resulting from the dialectical relation that interconnects ideology and utopia, by interpreting it as a temporal dialectics between external historical testimonies (witnesses) of the absolute and the internal witnessing of conscience. Because the latter turns to be attentional in nature, it accomplishes a mastery over time which consists in the mediation between the space of experience and indebtedness, on the one hand, and the horizon of expectation, the bearing of one's own acts, on the other. It operates "the incessant transaction" between the task of bringing "purely utopian expectations into connection with the present by strategic action concerned to take the first steps in the direction of the desirable and the reasona- 
ble" and resisting "the narrowing of our space of experience by liberating the unused potentialities of the past" (Ricoeur 1988, 235). In other words, conscience understood in terms of attention works so as to neutralise the overwhelming impact of the past, to liberate oneself from its charge, but at the same time, to assure continuity on the motivational level, and to draw on all of our mobilising resources in order to open up the future. Besides, it interrupts the endless consideration of mere possibilities by focusing on a chosen one, and by making a decision in accordance with the principle of the first steps, albeit small and concrete, towards what is denoted as an absolute. This is because "utopias are wholesome only to the extent that they contribute to the interiorization of changes" (Ricoeur 1986, 314). The exterior testimonies or witnesses attest that a certain way of acting is not only realisable but may also be attractive.

There is a supplementary criterion that one can find in the Ricoeurian analysis of the link between religion and symbolic violence. In fact, conscience remains a human capacity and, as such, it entails the coexistence of finiteness and of infinity. These two factors may be termed a finite capacity of reception, appropriation, or adherence in the first instance, or something fundamental, an abyssal ground, a superabundant source, in terms of the second (Ricoeur 1999, 2-11). The additional sought-for criterion emerges directly from the unavoidable tension between these anthropological components. The problem begins precisely when the excess characteristic of the source of human summons, owing to an appropriative desire, starts to become a threat. It gives rise to the endeavour to master the source at all costs. One might compare this process to a selfprotective "attempt to force the spring to adapt itself to the dimensions of the vase" (Ricoeur 1999, 4); to level the constitutive anthropological disproportion. What is more, any other way of grasping the fundamental appears to be in competition, leading to its exclusion. The criterion in question serves to prevent such a scenario. As a result, listening to the "voice" of conscience representing the interior absolute in search of its historical counterparts requires one to respect two imperatives: "deepening of conviction regarding the groundless ground and reinforcing the criticism of exclusionary impulses, with the help of the figure or figures most capa- 
ble of dismantling the scapegoat mechanism" (Ricoeur 1999, 11). It seems that this criterion can be summarised in terms of the inexhaustibility of the fundamental, which in turn implies an inclusiveness of its testimonies, an unceasing openness of their set, and the unifying function of referring to them. Such a dual initiative springs from an abundance of experience that spans centuries.

\section{Conclusion}

In this paper, I chiefly intended to explore the anthropological foundations of conscience as an attentional mode of being oneself. As a result, it transpired that conscience works by affirming the existence of some deeper resources in humans than those resulting from the past, from the bond with it, and its determining influence. These resources attest to the possibility of a different new beginning, of liberating other potentialities lying in the past. Simultaneously, conscience mediates - in the sense of designing - between this lived past, creating a space of experience and the future-oriented horizon of expectation by somehow imagining the next concrete steps to be taken. Thus, this human attentional capacity of discernment manifests something of a teleological trait that is not reducible to a deontological and purely moral, or even moralistic, view.

Even if conscience is closely intertwined with attention, they are far from identical to one another. The specificity or uniqueness of conscience in comparison with attention lies in its mediatory function with regard to the three temporal dimensions. It is a kind of mediation that enables a situationally suitable action, i.e. allowing a progressive achievement of what is in the greatest accessible conformity with an externally and internally witnessed absolute here and now. Additionally, this mediatory role consists of balancing the excessively ideological or utopian tendencies at play in bringing an action about. It works so as to preserve the inexhaustibility of the fundamental, and to keep oneself open and approving the testimonies that appear throughout the lived time.

Since these testimonies require an acknowledgement, some signs or attitudes should be recognised in their power of witnessing, which presup- 
poses their understanding as such, followed by an inchoative judgment. It entails that conscience is neither simple immediacy nor pure reflexion both are indispensable in decoding this double initiative, by means of the heritage coming from the past. In this way, conscience serves to reconcile the critical aspect of attention as a mode of perception (in a broader sense) with that of conviction, which permits an end to constant deliberation, and enables us to choose. By the same token, it reconciles human existential finiteness with their infinite resources. As a result of this endeavour, and because it mobilises the foundations going back to the immemorial past, it deserves to be termed "a small miracle of recognition" (Ricoeur 2006, 39, 495, 497, 502).

\section{References}

Foucault, Michel. 2014. Wrong-Doing, Truth-Telling: The Function of Avowal in Justice, edited by Fabienne Brion and Bernard E. Harcourt. Translated by Stephen W. Sawyer. Chicago: The University of Chicago Press.

Grzywacz, Robert. 2020. Świadek przekonań - podmiot sumienia. Paul Ricoeur i filozofia świadectwa. Kraków: Wydawnictwo Księgarnia Akademicka.

Hadot, Pierre. 1995. Philosophy as a Way of Life: Spiritual Exercises from Socrates to Foucault. Translated by Michael Chase. Oxford: Blackwell Publishers.

Hayes, Steven C. and Spencer Smith. 2005. Get Out of Your Mind \& Into Your Life. The New Acceptance \& Commitment Therapy. Oakland: New Harbinger Publications, Inc.

Heidegger, Martin. 2010. Being and Time. Translated by Joan Stambaugh. Albany: State University of New York Press.

Johnson, Michael A. 2018. "The Paradox of Attention. The Action of the Self upon Itself." In A Companion to Ricoeur's Freedom and Nature, edited by Scott Davidson, 79-108. Lanham: Lexington Books.

Lubowicka, Grażyna. 2000. Sumienie jako poświadczenie: Idea podmiotowości w filozofii Paula Ricoeura. Wrocław: Wydawnictwo Uniwersytetu Wrocławskiego.

Ricoeur, Paul. 1966. Freedom and Nature: The Voluntary and the Involuntary. Translated by Erazim V. Kohak. Evanston: Northwestern University Press.

Ricoeur, Paul. 1980. Essays on Biblical Interpretation, edited by Lewis S. Mudge. Translated by David Pellauer, David Stewart, Charles E. Reagan. Minneapolis: Fortress Press. Prepared for Religion-Online by Harry W. and Grace C. Adams 
(https://www.religion-online.org/book/essays-on-biblical-interpretation/ 8.12.2019).

Ricoeur, Paul. 1984. Time and Narrative. Vol. 1. Translated by Kathleen McLaughlin and David Pellauer. Chicago: The University of Chicago Press.

Ricoeur, Paul. 1986. Lectures on Ideology and Utopia. New York: Columbia University Press.

Ricoeur, Paul. 1988. Time and Narrative. Vol. 3. Translated by Kathleen Blarney and David Pellauer. Chicago: The University of Chicago Press.

Ricoeur, Paul. 1991. From Text to Action: Essays in Hermeneutics, II. Translated by Kathleen Blamey, John B. Thompson. Evanston: Northwestern University Press.

Ricoeur, Paul. 1992. Oneself as Another. Translated by Kathleen Blamey. Chicago: The University of Chicago Press.

Ricoeur, Paul. 1995. Figuring the sacred: religion, narrative, and imagination. Translated by David Pellauer. Minneapolis: Fortress Press.

Ricoeur, Paul. 1999. "Religion and Symbolic Violence." Translated by James Williams. In Contagion: Journal of Violence, Mimesis, and Culture 6: 1-11.

Ricoeur, Paul. 2006. Memory, history, forgetting. Translated by Kathleen Blamey and David Pellauer. Chicago: The University of Chicago Press.

Ricoeur, Paul. 2008. Amour et justice. Paris: Editions Points.

Ricoeur, Paul. 2016. Philosophical Anthropology: Writings and Lectures. Vol. 3, edited by Johan Michel and Jérôme Porée. Translated by David Pellauer. Cambridge: Polity Press.

Roy, Louis. 2003. "Reference and Testimony: Paul Ricoeur's Approach to Revelation.” In Between Suspicion and Sympathy. Paul Ricoeur's Unstable Equilibrium, edited by Andrzej Wierciński, 285-301. Toronto: The Hermeneutics Press.

Spaemann, Robert. 2006. Persons: The Difference between 'Someone' and 'Something'. Translated by Oliver O’Donovan. Oxford: Oxford University Press.

Zimbardo, Philip G., Robert L. Johnson, and Vivian McCann. 2017 (8th ed.). Psychology: Core Concepts. New York: Pearson.

Ziółkowska, Anna. 2007. "Hermeneutyczna wykładnia sumienia (Heidegger Ricoeur).” Diametros: A Journal of Philosophy 13: 58-90. 